\title{
Molecular typing of bacteria of the genus Asaia in malaria vector Anopheles arabiensis Patton, 1905
}

\author{
S. Epis, $, 1,2$ M. Montagna, ${ }^{2}$ F. Comandatore, ${ }^{2}$ C. Damiani, ${ }^{1}$ A. Diabaté, ${ }^{4}$ D. Daffonchio, ${ }^{3}$ \\ B. Chouaia, ${ }^{3}$ G. Favia' ${ }^{1}$
}

\begin{abstract}
${ }^{1}$ Scuola di Bioscienze e Biotecnologie, Università degli Studi di Camerino; ${ }^{2}$ DIVET, Università degli Studi di Milano; ${ }^{3}$ DEFENS, Università degli Studi di Milano, Italy; ${ }^{4}$ Institut de Recherche en Science de Santé/Centre Muraz, Bobo-Dioulasso, Burkina Faso
\end{abstract}

\begin{abstract}
The acetic acid bacterium Asaia spp. was successfully detected in Anopheles arabiensis Patton, 1905, one of the major vector of human malaria in Sub-Saharan Africa. A collection of 45 Asaia isolates in cellfree media was established from 20 individuals collected from the field in Burkina Faso. 16S rRNA universal polymerase chain reaction (PCR) and specific qPCR, for the detection of Asaia spp. were performed in order to reveal the presence of different bacterial taxa associated with this insect. The isolates were typed by internal transcribed spacer-PCR, BOX-PCR, and randomly amplified polymorphic DNA-PCR, proved the presence of different Asaia in A. arabiensis.
\end{abstract}

\section{Introduction}

Species of the genus Anopheles Meigen, 1818 are the most important vectors of malaria in Sub-Saharan Africa. Within the Anopheles gambiae complex, composed of seven morphologically indistinguishable species of mosquitoes, Anopheles arabiensis Patton, 1905 and Anopheles gambiae Giles, 1902 sensu strictu show the wider distribu-

Correspondence: Bessem Chouaia, DEFENS, Università degli Studi di Milano, Via Celoria 2, 20133 Milano, Italy.

Tel: +39.02.5031.9068 - Fax: +39.02.5031.6694.

E-mail: bessem.chouaia@unimi.it

Key words: Anopheles arabiensis, mosquito-associated bacteria, Asaia spp., molecular typing.

Acknowledgements: this work was supported by Firb-Ideas (grant RBID082MLZ).

Received for publication: 31 May 2012.

Revision received: 18 July 2012.

Accepted for publication: 19 July 2012.

(C)Copyright S. Epis, 2012

Licensee PAGEPress, Italy

Journal of Entomological and Acarological Research 2012; 44:e7 doi:10.4081/jear.2012.e7

This article is distributed under the terms of the Creative Commons Attribution Noncommercial License (by-nc 3.0) which permits any noncommercial use, distribution, and reproduction in any medium, provided the original author(s) and source are credited. tion and are the most efficient malaria vectors (Onyabe \& Conn, 2001a and 2001b). A. arabiensis prefers tropical weather and its typical habitat is the dry Savannah, reproducing in natural and artificial puddles of water, but can fly for more than two kilometers from its place of birth. A. arabiensis population density varies depending on climate conditions during the year; the adults show the minimum density between March and June, while after the first rains in July reach the highest levels (i.e. August and September) then decrease in October (Robert et al., 1998). The presence of $A$. arabiensis is favored by temperatures of $28-30^{\circ} \mathrm{C}$, clean water, high concentrations of $\mathrm{HCO}_{3}{ }^{-}$and $\mathrm{CO}_{3}{ }^{2-}$, low concentrations of $\mathrm{NO}_{3}{ }^{-}$and $\mathrm{NaCl}$, absence of predatory invertebrates and fish (as Gambusia and Tilapia), presence of plants of the genus Pistia (water lettuce) and absence of those of the genus Lemna (duckweed) (Robert et al., 1998). A. arabiensis is the only vector of malaria in Dakar, Senegal, and is predominant in Ethiopia, Sudan and in the Guinean Savannah. A. gambiae is vicariant of A. arabiensis in the Sub-Saharan region not colonized by the latter. In the last 20 years, A. arabiensis has expanded its distribution, spreading even in forests where $A$. gambiae was prevalent, probably because of climate change (Onyabe \& Conn, 2001a; Donnelly et al., 2001). Hargreaves and colleagues (2003) demonstrated that $A$. arabiensis is resistant to DDT, one of the major insecticides used in malaria control program. As a result of these data, in order to control the vector, it is important to develop new integrated strategies. Similar to a recently described work (Chouaia et al., 2010), here we present the first description of the symbiont Asaia in A. arabiensis mosquitoes and its genetic diversity.

Asaia is a Gram-negative acetic acid bacterium associated with different genera of insect (Favia et al., 2007; Crotti et al., 2009; Damiani et al., 2010). It has been found in the gut, salivary glands, and reproductive organs; it is transmitted vertically, horizontally and venereally from males to females. Recently, it has been demonstrated that Asaia is not transmitted to humans (Epis et al., 2011) suggesting that Asaia could be regarded only as an opportunistic pathogens and a good candidate to potentially vector antiplasmodial factors (Favia et al., 2008; Ricci et al., 2010). Uncovering the level of diversity of the symbiont Asaia of A. arabiensis would be useful for potential applications by allowing the selection of the dominant genotypes, that in this case represents the most widespread genotype among the insect populations, in order to develop paratransgenic approaches.

\section{Material and methods}

\section{Mosquito strains origin}

A. arabiensis was collected from Soumousso and Vallée du Kou (Burkina Faso), immediately stored in enrichment medium, and sent 
to the University of Camerino (Italy). Furthermore, 20 females collected from the same localities were reared in Burkina Faso insectary; the laid eggs were sent and maintained in the insectary of the Laboratory of Parasitology at the University of Camerino in order to start the new colony.

\section{Isolation of Asaia from A. arabiensis}

Asaia strains were isolated from adult mosquitoes using the enrichment medium I as described by Lisdiyanti et al, 2001. A. arabiensis samples were washed in $1 \%$ sodium hypochlorite for 1 min, subsequently washed three times with $0.9 \% \mathrm{NaCl}$, and homogenized by grinding in $200 \mu \mathrm{L} 0.9 \% \mathrm{NaCl}$. The homogenate was inoculated into the enrichment medium and allowed to grow at $30^{\circ} \mathrm{C}$ for 3 days, with shaking. When microbial growth occurred, the microorganisms were streaked on $\mathrm{CaCO}_{3}$ agar plates ( $\mathrm{pH} 6.8$ ) containing $1.0 \%$ (wt/vol) d-glucose, $1.0 \%$ (wt/vol) glycerol, 1.0\% (vol/vol) ethanol, 1.0\% (wt/vol) bactopeptone, $0.5 \%$ (wt/vol) yeast extract, $0.7 \%$ (wt/vol) $\mathrm{CaCO}_{3}$, and $1.5 \%$ (wt/vol) agar as reported in Chouaia et al., 2010. After 3 days growth, the colonies were collected. After the incubation period, $500 \mu \mathrm{L}$ of enriched broth containing the Asaia have been preserved in a solution of $16 \%$ glycerol. The glycerine obtained were placed at $-80^{\circ} \mathrm{C}$ for storage.

\section{DNA extraction and amplification from selected colonies}

DNA was extracted from Asaia strains and mosquitoes using commercial kit Wizard Genomic DNA Purification (PROMEGA Corp., Fitchburg, WI, USA) and eluted in $100 \mu \mathrm{L}$ of elution buffer. The quantitative polymerase chain reaction (qPCR) screening of mosquitoes, for the specific detection of Asaia spp., were performed with IQ thermal cycler (Bio-Rad, Hercules, CA, USA) using the previously described primers Asafor (5 -GCGCGTAGGCGGTTTACAC) and Asarev (5 AGCGTCAGTAATGAGCCAGGTT) (Favia et al., 2007). The 16S rRNA gene was PCR amplified with universal bacterial 16S rRNA gene primers 27F (5 -TCGACATCGTTTACGGCGTG) and 1492R (5 -CTACGGCTACCTTGTTACGA).

Internal transcribed spacer (ITS)-PCR was performed, with primer ITSF (5 -GCCAAGGCATCCAAC) and ITSR (5 -GTCGTAA CAAGGTAGCCGTA) (Daffonchio et al., 1998). The BOX-PCR was performed, with BOX-A1 primer (5 -CTACGGCAAGGCGACGCTGAC) according to Urzì et al., 2001; randomly amplified polymorphic DNA (RAPD)-PCRs were performed, using the RAPD OPA4 (5-AATCGGGCTG) and OPA10 (5GTGATCGCAG) primers (Daffonchio et al., 1998).

\section{Sequence analysis}

Nucleotide identity searches were performed in the GenBank database using the basic local alignment search tool (BLAST; http://blast. ncbi.nlm.nih.gov/Blast.cgi) program to identify the bacterial strains most closely related to isolates and the best matching DNA sequences of the sequenced amplicons. A phylogenetic tree based on the analysis of the $16 \mathrm{~S}$ rRNA sequences was inferred using the neighbor-joining method (Saitou et al., 1987) with 1000 replicates as a bootstrap test and visualized using Mega 4 (Tamura et al., 2007), the 16S rRNA sequence of Acetobacter tropicalis BA 1.3 was used as an outgroup. The 16S rRNA gene sequences were deposited under accession numbers from HE814602 to HE814621 in the European Molecular Biology Laboratory Nucleotide Sequence Database (http://www.ebi.ac.uk/).

\section{Cluster analysis}

PCR fingerprintings were obtained by visualization, under UV light, of $1.2 \%$ of agarose gel electrophoresis. The profiles were analyzed using the Quantity One ${ }^{\circledR}$ software (version 4.6.5, Bio-Rad). For each strain profile, a matrix, reporting the presence $(1)$ or absence $(0)$ of bands at a specific distance, was generated. The analysis of profiles of
ITS-PCR, BOX-PCR and RAPD-PCRs allowed obtaining a genotypic profile for each strain. To estimate the level of similarity between the strains based on the merged profiles obtained from ITS-PCR, BOX-PCR, and RAPD-PCR, and to create the Unweighted Pair Group Method with Arithmetic Mean (UPGMA) tree, MVSP software (version 3.13n, Kovach Computing Services, Pentraeth, Isle of Anglesey, UK) was used (Dunn and Everitt, 1982).

\section{Results}

Forty-five isolates of Asaia spp. were obtained from 20 mosquitoes. The sequences obtained by universal bacterial $16 \mathrm{~S}$ rRNA PCR confirmed the presence of Asaia spp. in A. arabiensis mosquitoes. Moreover, specific qPCR carried on A. arabiensis showed the presence of this bacterium associated to the studied population; Asaia 16S rRNA gene copies was abundant in all DNAs extracted from $A$. arabiensis mosquitoes, with a mean of $7.8 \times 10^{5}$ Asaia $16 \mathrm{~S}$ rRNA gene copies for single individual.

The 45 Asaia isolates from the mosquitoes exhibited the same ITSPCR fingerprinting profiles, presenting an amplification pattern consisting of 3 bands between 500 and 3700 bp (data not shown). The RAPD-PCR using the primer set OPA4 and OPA10 revealed, respectively, four and three genotypes characterized by complex band patterns between 450 and $7300 \mathrm{bp}$. The analysis obtained from BOX-PCR showed several profiles among the strains examined. BOX-PCR discriminated from 4 to 6 band pattern types, with most of the bands in the range between 350 and $4500 \mathrm{bp}$.

By using the software Quantity One, for each strain, a band profile was obtained from the analysis of the agarose gels of the amplifications carried out on the genome of Asaia from A. arabiensis. The merging of the results obtained from all the four PCRs (ITS-PCR, BOX-PCR and RAPD-PCRs) allowed us to distinguish 21 genotype patterns. The tree generated with the UPGMA methods using the Jaccard coefficient allowed clustering the different profiles in a tree (Figure 1). From the analysis of this tree it was possible to identify 9 groups (from I to IX).

Table 1. Different groups and relative profile numbers and Asaia strains.

\begin{tabular}{lcc} 
Groups & Profile numbers & Asaia strains \\
I & 1 & 1 \\
& 2 & $2,3,4,5$ \\
II & 3 & 12 \\
& 4 & $7,8,9,11$ \\
& 5 & 10 \\
III & 6 & 6 \\
& 7 & 15,16 \\
IV & 8 & $14,17,18$ \\
V & 9 & $19,20,21,22$ \\
VI & 10 & 13 \\
& 11 & 36,37 \\
& 12 & 27,28 \\
VII & 13 & $29,30,31$ \\
& 14 & $32,33,34$ \\
VIII & 15 & 35 \\
& 16 & $23,24,25$ \\
& 17 & 39 \\
IX & 18 & $40,41,43$ \\
& 19 & 42 \\
\hline
\end{tabular}




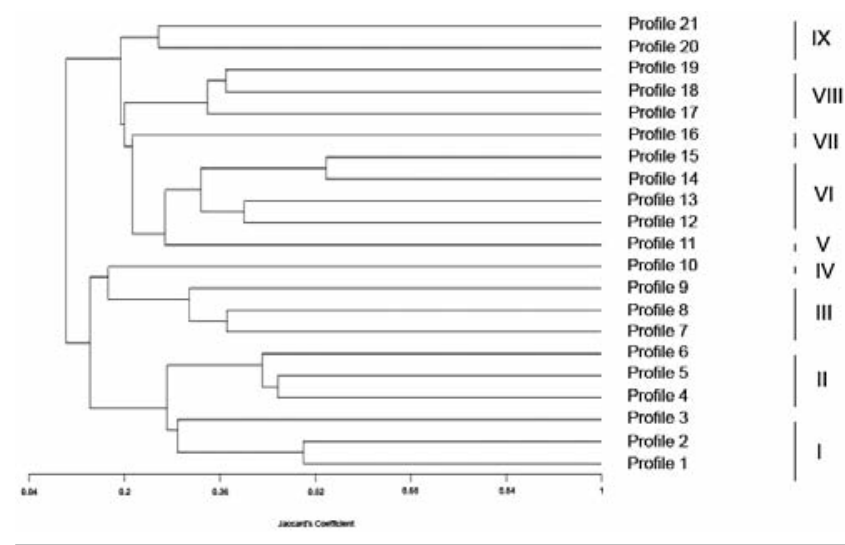

Figure 1. Similarity tree between the profiles of Asaia spp. isolated from the Anopheles arabiensis mosquitoes. The tree was generated with the Unweighted Pair Group Method with Arithmetic Mean methods using the Jaccard coefficient. We can distinguish 9 groups (from I to IX).
The analysis of the data allowed also to identify two more abundant strains (groups III and VI) each of them grouping $20 \%$ of the total strains (Table 1). Those stains were present in all studied populations of mosquito and not restricted to only one individual. Other strains were also present in more than one mosquito like the groups I, II and VII. Except for the group IV all the other groups were represented by more than one isolate present in more than one mosquito.

The phylogenetic tree based on the partial 16S rRNA sequence of representative strains of Asaia isolated for A. arabiensis showed that the strains clustered with other strains of Asaia krungthepensis (Figure 2). The phylogenetic analysis of the 16S rRNA did not show a high diversity of the strains as compared to the results of the molecular typing based on DNA markers (Figure 1).

\section{Discussion and conclusions}

Previous studies have shown that $A$. stephensi (Favia et al., 2007), Aedes aegypti, A. gambiae, Ae. albopictus mosquitoes (Chouaia et al., 2010) and Scaphoideus titanus (Crotti et al., 2009) host the bacterium Asaia. Here we demonstrate the presence of acetic acid bacteria Asaia both in males and in females mosquitoes of $A$. arabiensis. The fact that Asaia is also able to be transmitted horizontally and cross colonize different species (Damiani et al., 2008; Crotti et al., 2009) may suggest the capacity of Asaia to be environmentally transmitted between $A$. arabiensis and $A$. stephensi.

In order to obtain a genetic profile of each strain of Asaia, the DNA was amplified using BOX-PCR, RAPD-PCRs and ITS-PCR. Based on these profiles, a similarity tree was build. This analysis showed that, in A. arabiensis, Asaia strains clustered in 21 different genotypes that can be grouped into 9 clusters. This study showed that the same A. arabiensis mosquito may harbor simultaneously different strains of the symbiont and that each strain of Asaia can colonize more than a single specimen of $A$. arabiensis. A similar multiple infection phenomena have been reported in other mosquito species harboring Asaia (Chouaia et al., 2010) and insects associated with the symbiont Wolbachia (Werren et al., 1995). The strains isolated in this work display a higher diversity (21 genotypes from 45 strains) than those studied in the work of Chouaia et al., 2010 using BOXPCR, RAPD-PCRs, tRNA-PCR and ITS-PCR (29 genotypes from 284 strains). The detected higher diversity can be explained by the fact that, unlike the mosquito species studied by Chouaia et al. (2010), the population of $A$. arabiensis studied in this work is a wild population. The mosquito associated Asaia is a secondary symbiont that may be acquired from the environment (Damiani et al., 2008; Chouaia et al., 2012). In spite of the stable lab rearing concentrations, the natural environment present complex interactions both at the biotic and abiotic levels, thus bacterial populations displaying high diversity have higher chance to adapt and survive in new environmental conditions (have higher chance of adaptations and survival in a changing environment). The presence of Asaia in A. Arabiensis, the most important malaria vector in Sub-Saharan Africa, can lead to the possibility to use this symbiont in a paratransgenesis approach as support for the prevention of malaria transmission.

In devising a paratransgenic approach it is essential to consider the genetic heterogeneity of the bacterium Asaia and the lack of a predominant strain in A. arabiensis.

\section{References}

Figure 2. Phylogenetic positions of the strains of Asaia isolated from $A n$ arabiensis, based on $16 S$ rRNA gene sequences (Neighbor joining method; Kimura correction; all positions containing gaps and missing data were eliminated from the data set). Values of bootstrap superior to $60 \%$ have been reported in the tree. The scale bar represents sequence divergence. The 16S rRNA sequence of Acetobacter tropicalis strain BA 1.3 was used as outgroup.
CHOUAIA B., ROSSI P., EPIS S., MOSCA M., RICCI I., DAMIANI C., et al., 2012 - Delayed larval development in Anopheles mosquitoes deprived of ASAIA bacterial symbionts. - BMC Microbiol. 12 (Suppl 1): $S 2$. 
CHOUAIA B., ROSSI P., MONTAGNA M., RICCI I., CROTTI E., DAMIANI C., et al., 2010 - Molecular evidence for multiple infections as revealed by typing of Asaia bacterial symbionts of four mosquito species. - Appl. Environ. Microbiol. 76: 7444-7450.

CROTTI E., DAMIANI C., PAJORO M., GONELLA E., RIZZI A., RICCI I., et al., 2009 - Asaia, a versatile acetic acid bacterial symbiont, capable of cross-colonizing insects of phylogenetically distant genera and orders. - Environ. Microbiol. 11: 3252-3264.

DAFFONCHIO D., BORIN S., FROVA G., MANACHINI P.L., SORLINI C., 1998 - PCR fingerprinting of whole genomes: the spacers between the $16 \mathrm{~S}$ and $23 \mathrm{~S}$ rRNA genes and of intergenic tRNA gene regions reveal a different intraspecific genomic variability of Bacillus cereus and Bacillus licheniformis [corrected]. - Int. J. Syst. Bacteriol. 48: 107-116.

DAMIANI C., RICCI I., CROTTI E., ROSSI P., RIZZI A., SCUPPA P., et al., 2008 - Paternal transmission of symbiotic bacteria in malaria vectors. - Curr. Biol. 18: R1087-1088.

DAMIANI C., RICCI I., CROTTI E., ROSSI P., RIZZI A., SCUPPA P., et al., 2010 - Mosquito-bacteria symbiosis: the case of Anopheles gambie and Asaia. - Microb. Ecol. 60: 644-654.

DONNELLY M.J., LICHT M.C., LEHMANN T., 2001 - Evidence for recent population expansion in the evolutionary history of the malaria vectors Anopheles arabiensis and Anopheles gambie. - Mol. Biol. Evol. 18: 1353-1364.

DUNN G., EVERITT B.S., 1982 - An Introduction to Mathematical Taxonomy. - Cambridge University Press, Cambridge, UK.

FAVIA G., RICCI I., DAMIANI C., RADDADI N., CROTTI E., MARZORATI M., et al., 2007 - Bacteria of the genus Asaia stably associate with Anopheles stephensi, an Asian malarial mosquito vector. - Proc. Natl. Acad. Sci. U S A. 104: 9047-9051.

FAVIA G., RICCI I., MARZORATI M., NEGRI I., ALMA A., SACCHI L., et al., 2008 - Bacteria of the genus Asaia: a potential paratransgenic weapon against malaria. - Adv. Exp. Med. Biol. 627: 49-59.

HARGREAVES K., HUNT R.H., BROOKE B.D., MTHEMBU J., WEETO M.M., AWOLOLA T.S., et al., 2003 - Anopheles arabiensis and A. quadriannulatus resistance to DDT in South Africa. - Med. Vet. Entomol. 17: 417-422.

LISDIYANTI P., KAWASAKI H., SEKI T., YAMADA Y., UCHIMURA T., KOMAGATA K., 2001 - Identification of Acetobacter strains isolated from Indonesian sources, and proposals of Acetobacter syzygii sp. nov., Acetobacter cibinongensis sp. nov., and Acetobacter orientalis sp. nov. - J. Gen. Appl. Microbiol. 47: 119-131.

ONYABE D.Y., CONN J.E., 2001a - Population genetic structure of the malaria mosquito Anopheles arabiensis across Nigeria suggests range expansion. - Mol. Ecol. 10: 2577-2591.

ONYABE D.Y., CONN J.E., 2001b - The distribution of two major malaria vectors, Anopheles gambie and Anopheles arabiensis, in Nigeria. - Mem. Inst. Oswaldo Cruz. 96: 1081-1084.

RICCI I., DAMIANI C., ROSSI P., CAPONE A., SCUPPA P., CAPPELLI A., et al., 2010 - Mosquito symbioses: from basic research to the paratransgenic control of mosquito-borne diseases. - J. Appl. Entomol. 135: 487-493.

ROBERT V., AWONO-AMBENE H.P., THIOULOUSE J., 1998 - Ecology of larval mosquitoes, with special reference to Anopheles arabiensis (Diptera: Culicidae) in market-garden wells in urban Dakar, Senegal. - J. Med. Entomol. 35: 948-955.

SAITOU N., NEI M., 1987 - The neighbor-joining method: a new method for reconstructing phylogenetic trees. - Mol. Biol. Evol. 4: 406-425.

TAMURA K., DUDLEY J., NEI M., KUMAR S., 2007 - MEGA4: Molecular Evolutionary Genetics Analysis (MEGA) software version 4.0. - Mol. Biol. Evol. 24: 1596-1599.

URZİ C., BRUSETTI L., SALAMONE P., SORLINI C., STACKEBRANDT E., DAFFONCHIO D., 2001 - Biodiversity of Geodermatophilaceae isolated from altered stones and monuments in the Mediterranean basin. Environ. Microbiol. 3: 471-479.

WERREN J.H., ZHANG W., GUO L.R., 1995 - Evolution and phylogeny of Wolbachia: reproductive parasites of arthropods. - Proc. Biol. Sci. 261: 55-63. 